\title{
San Agustín y la unidad de los cristianos
}

\begin{abstract}
"Sic ejus (Ecclesiae) teneant unitatem, ut non solum viam salutis inveniant, sed nec honorem episcopatus amittant. Neque enim in eis divinae Sacramenta veritatis, sed commenta humani detestamur erroris: quibus sublatis fraternum pectus amplectimur, christiana nobis caritate conjuctum, quod nunc dolemus dissensione diabolica separatum".
\end{abstract}

(San Agustín, Ep. 182, 2.)

Sumario: La "unidad de los cristianos", aunque de colorido moderno, tiene sustancia antigua. San Agustín fue un maestro en el tratamiento de este pro. blema. Tiene, 'además, títulos especiales para unir a los cristianos, ya que todos le aman e invocan. Es pues interesante en nuestros días conocer las conclusiones a que llegó San Agustín y los principios en que se apoyó su noble pensamiento.

Colocar un tema moderno en una perspectiva del pasado y en relación con hombres de otro tiempo des parace a muchos una cuestión errada y carente de sentido a la vez que de juicio crítico. Parece como si ser moderno llevara consigo renunciar a todo el pasado y caminar sin pie firme, pensar en el pasado con una visión relativística en el sentido de que todo aquello sólo ha sucedido una vez y todos los hombres que han vivido antes, solamente tenían algo que decir a su tiempo, cosas que por otra parte hoy no nos sirven más. Todo sería relativo y sería necesario interpretarlo en conformidad con las circunstancias, el tiempo, la mutabilidad de todo lo humano. Es verdad que toda doctrina o al menos toda exposición o manifestación de la misma posee una gran parte de mudable en cuanto que la expresión cambia con el tiempo, pero es itambién verdadero que la idea profunda, las posturas, la experiencia vital pueden siempre servir y pueden dar su contribución a la historia sea del pensamiento, sea de la actividad humana. Todo aquello que ha pasado conserva también un significado para la posteridad y es susceptible de un confrontamiento, siempre útil, en cuanto que puede enseñar los orígenes de ciertas actitudes. Ser moderno no es mirar todo con ojos 
relativísticos, sino caminar hacia el futuro fundados en la auténtica tradición.

Tratar el tema de la unidad en San Agustín sería para algunos querer imponer categorías nuevas a un pensamiento antiguo. San Agustín serviría para su tiempo y hoy no tendría nada que decirnos sobre el particular. Es verdad que Agustín no habla, al igual que los otros Padres de la Iglesia, del ecumenismo en estos términos, ni de diálogo ecuménico. No ha escrito ningún tratado sobre el movimiento ecuménico, ni menos aún sobre los principios del ecumenismo. $\mathrm{Y}$ sin embargo, a través de toda su vida ha desarrollado una intensa aotividad ecuménica, o si queremos mejor, ha luchado como ningún otro por la unidad cristiana, ha sufrido en carne propia el "escándalo de la división de los cristianos" en el Africa de su tiempo, afectada por las discordias y desótdenes religiosos *.

No es secreto para nadie: El problema de la división en las religiones es tan antiguo, estaba por decir, como la misma religión. Se ha dejado ver ya en el Antiguo Testamento, y se trataba tanto de división interna como externa. No todos estaban de acuerdo con los preceptos del Señor y sobre todo con aquella religión de tantas exigencias. Pero pasando a la Iglesia de Dios, el mismo Concilio nos recuerda, después de haber expresado la unidad que Cristo vino a restituir, difundiendo el Espíritu Santo, fundando la Iglesia e instituyendo los Doce bajo la autoridad de Pedro: "Ya desde los comienzos surgieron escisiones en esta una y única Iglesia de Dios (cf. I Cor II, I8-19; Gal I, 6-9; I Jo 2, I8-I9), las cuales reprueba gravemente el Apóstol como condenables (cf. I Cor I, II ss. 2); y en sigilos posteriores nacieron disensiones más amplias, y Comunidades no pequeñas se separaron de la plena comunión de la Iglesia católica, a veces no sin culpa de los hombres de una y de otra parte" ${ }^{1}$. La historia de la Iglesia está sembrada de estas divisiones, pero también ante estas divisiones se encuentran reclamos a la unidad, tanto de una como de otra parte. No han faltado nunca pastores celosos, fieles a las palabras de Cristo, que con sus voces potentes y sus escritos, han trabajado en bien de la unidad.

Quizá la unidad de los cristianos como problema específico teológico es más bien de contextura moderna, pero como práctica y más todavía

* Cfr. A. Turrado, “El Escándalo de la división. Rayos de luz entre penumbras": Religión y Cultura 6 (1961) 365-415; 7 (1962) 29-60.

1 Decr. Unitatis redintegratio I, 3. 
como vida es antiguo y ha estado profundamente anclado en los espíritus de los más grandes Pastores. La historia del pensamiento y de la actuación pastoral nos puede enseñar mucho a este respecto, y la especulación teológica puede enriquecernos y hacernos profundizar, hundiendo sus raíces en la experiencia de esos grandes hombres.

San Agustín lazo de unión.

Un maestro para este objetivo de la unidad, lo tenemos abiertamente en San Agustín. Sin entrar ahora en la postura que tomó hacia los hermanos "separados", ni siquiera en su doctrina sobre el particular, podemos decir sin más, que Agustín, ya de por sí, como hombre, puede ser, incluso para hoy, como un lazo de unión entre los cristianos divididos al presente. Bastaría una visión de conjunto, para darse cuenta de que todos lo invocan como a defensor de las propias doctrinas, y de que tanto los católicos como los demás cristianos - a veces más los otros que los católicos- recurren a sus obras para probar la propia fe. Y poidría decirse que Agustín se encuentra en medio, en el equilibrio entre las diversas interpretaciones parcialistas. El parcialismo puede existir en ambas partes, ya que San Agustín en sus obras, tiene un continuo doble punto de vista en cuya unidad se halla él plenamente, aunque esa unidad no la haya frecuentemente realizado. Sería errado el creer a Agustín, todo él, sólo en una parte, como sólo en otra. La causa unionística descubriría en la doctrina agustiniana su verdadera fuente, ya que al comienzo de casi todas las divisiones nos encontramos con Agustín. Estudiado desde este ángulo de visión, ni polémico ni apologético, sino abierto y sincero, sería el lazo más seguro entre los cristianos.

Pero, dejando a un lado estas razones de tipo general sobre el problema de la unidad, Agustín ha desarrollado una actividad unionística intensísima y de esta misma actividad ha extraído una experiencia. Podemos incluso pensar que su actividad interior ha sido dirigida por una ideología en torno al problema que le preocupaba y le hacía sufrir. De ondinario el argumento se ha situado desde la controversia donatista $^{2}$, que es sin duda la más interesante, pero se necesita abrir un poco

2 Vid. J. VoDopivec, "Irenical Aspects of St. Augustine's Controversy, with the Donatists": Studia Patristica VI, part. IV, edited by F. L. Cross, 519-532, Berlin 1962; A. Turrado, a. c. 55-59, titula un apartado: "La lección de San Agustín". 
más este ángulo de visión y considerar la formación de Agustín, sus diversas actitudes en relación con aquellos que poseían una opinión diversa de la suya, su influjo en la discusión con los donatistas, para extraer las conclusiones sobre aquello que podríamos llamar sus principios sobre la unidad.

Adelantamos rápidamente que la unidad entre los mismos católicos se le ha presentado de continuo como un testimonio y que por todos los medios primordialmente trata de unir a los católicos entre sí -cosa con frecuencia olvidada- De aquí que proponga la unidad en la diversidad, el respeto a las costumbres de los demás, oponiéndose a los carismáticos que creen que lo único que se hace de bueno es aquello que ellos hacen ${ }^{3}$. Sus palabras en lo que a esto respecta son de una actualidad extraordinaria: "habla del ayuno y de otras costumbres en las diversas regiones y añade: "He oído frecuentemente, con dolor y con llanto, que muchos débiles se ven perturbados por la contenciosa obstinación de algunos hermanos, o por un temor superticioso, hermanos que en cosas que no pueden resultar seguras y ciertas, ni por la autoridad de la Sagrada Escritura, ni por la tradición de la Iglesia universal, ni por la utilidad de corregir la vida (sólo porque les viene a la cabeza cualquier argumento o porque están acostumbrados así a hacerlo en su patria, o porque lo han visto en otra parte, creyéndose tanto más sabios cuanto más lejos han viajado de los suyos), suscitan cuestiones tan arduas, que piensan recto sólo aquello que ellos hacen" ${ }^{4}$.

\section{SAN Agustín y la verdad.}

Si hay algo que hace impacto en una lectura asidua de las obras del Santo es precisamente su ansia de verdad, aquel deseo andiente de la verdad absoluta que inquieta el corazón de Agustín ya desde el principio. El mismo nos confesaba:

"Oh Verdad, Verdad, cómo ya entonces y desde las más íntimas fibras de mi corazón suspiraba por ti, mientras aquella gente (se habla de los maniqueos) me sacaba de mí frecuentemente y de varios modos con el solo sonido de tu nombre y la multitud de sus pesados volúmenes" 5 .

3 J. Morán. "San Agustín y los cambios en la Iglesia": Revista Agustiniana de Espiritualidad 8 (1967).

4 Epist. 54, 2, 3, PL. 33, 201.

5 Confess. III, 6, 10, PL. 32, 687. 
El suspiro de su alma venía guiado por el deseo y la sed íntima de la verdad, con una nobleza de espíritu nunca conocida, y con una sinceri$d a d$, que se atrevería a decir en el Contra Academicos, que "no cedería sino a la verdad" ". Si ha entrado en el maniqueísmo -convencido o no, no nos interesa de momento-, si no se ha encontrado a su gusto y ha querido dar en ciertos momentos la palma a los académicos, o la habría dado a los epicúreos, si se ha entregado a los platónicos y ha ido a oír a Ambrosio y se ha sometido a sus profundas palabras, lo ha hecho en honor a la verdad. Y ésta la buscaba con sinceridad.

Aun más, Agustín a sus diecinueve años ha leído el Hortensio, de Cicerón, pero él mismo nos recuerda que lo que más le ha gustado era que le invitaba a la misma sabiduría:

\footnotetext{
"Sin embargo -escribe Agustín-, sólo una cosa bastaba para encantarme en aquella incitación a la filosofía: sus palabras me estimulaban, me encendían, me inflamaban a amar, a buscar, a seguir, a conseguir, a abrazar vigorosamente no una $u$ otra secta filosófica, sino la sabiduría en sí y por sí allí donde estaba" ?.
}

Este libro cambió su manera de sentir y sus oraciones, pero sobre todo aquello que le ha impresionado fue esa exhortación a la sabiduría, no a esta o a la otra filosofía, sino la invitación a la sabiduría ${ }^{8}$. Agustín sufrirá rápidamente por la multitud de sectas filosóficas y tendrá siempre ante sus ojos esta exhortación del Hortensius. Desde este momento se interesará en la búsqueda de la verdadera, de la única sabiduría, y cuando la encuentre toda su vida se consumirá en comunicarla y en hacer partícipes a los otros de la misma.

Esta primera urgencia la ha sentido profundamente en su alma, ya que vemos, como nos refiere en todos los procesos de su conversión, que no ha cumplido aquellas exigencias que resonaron en su espíritu a la lectura del diálogo de Cicerón, y se lamentará del hecho. Fue una Ilamada intelectual y también moral. Fue la llamada a la verdad y a la unidad, y se pone de lleno a la búsqueda de la verdad, comenzando a leer la Sagrada Escritura, y pasando después al maniqueísmo por motivos no claros. Pero también en el aspecto moral, fue a la búsqueda de la unidad íntima que veía dividirse bien fuera bajo el peso de sus pasiones,

6 C. Acad. II, E, 16, PL. 32, 927.

7 Confess. III, 4, 8, PL. 32, 686 .

8 Vid. M. TestaRd, Saint Augustin et Cicerón I: Cicéron dans la formation et dans l'oeuvre de Saint Augustin, II: Répertoire des Textes, 2 vols., Paris 1958. 
o bajo sus múltiples actitudes psicológicas. Su conversión $-\mathrm{y}$ todo el proceso de la misma - no fue otra cosa que el huír de la multiplicidad de la dispersión hacia la unidad interior, escapar de la temporalidad hacia aquello que es interno y eterno, desentenderse de lo mudable para dirigirse hacia lo inmutable ${ }^{9}$.

Esta necesidad de unidad será puesta de relieve tanto en su vida monástica inicial como en la exposición de $A c t .4,32-35$, como en la eclesiología ${ }^{10}$. La potente llamada del neoplatonismo hacia la unidad lo perseguirá a través de toda su vida, y esta unidad se estructuraría tanto en el orden personal como en el social.

Hay todavía otro hecho que no podemos olvidar al intentar definir la lucha de Agustín por la unidad de los cristianos. El, sediento de verdad, se encuentra ante la relatividad de las doctrinas. Se ha dejado encantar un cierto tiempo a la espera de Fausto, pero Fausto le desilusiona. Agustín reposa en cierto sentido en los académicos, pero los académicos no estaban hechos para Agustín. El, a la búsqueda de la verdad absoluta no puede someter su juicio a una relatividad plena de la misma. Y de aquí que su primera obra, sus primeras cartas, e incluso en casi todos sus escritos, abundarán sobre el argumento contra los académicos para probarse la invención de verdad, y para darse razón a sí mismo de la validez de ella.

Agustín, por consiguiente, ha vivido en su propia alma el drama, y a veces, la tragedia de la unidad y de la verdad, y sabe y comprende cuánto cuesta realmente llegar hasta la fuente clara de donde mana lo verdadero, la vendad. Pero Agustín ha encontrado ya la verdad. Al final del libro VII de las Confesiones siente la tranquilidad de la verdad, y el Apóstol Pablo le descubre todo aquello que los filósofos le habían enseñado, pero aquí "cum commendatione gratiae", dice él. La humildad de la encarnación de Cristo se yergue ante la soberbia de los filósofos : Agustín, desde este instante, ya es cristiano ${ }^{11}$. La decisión del li-

9 Cfr. P. MuÑoz VEGA, Introducción a la síntesis de San Agustín, Roma 1945; J. MorÁN, "Del hombre a Dios": Religión y Cultura 5 (1960) 617-645; ID., El hombre frente a Dios, Valladolid 1963.

$10 \mathrm{Cfr}$. A. ManRIQUe, La vida monástica en San Agustín, Enchiridion histórico-doctrinal y Regla, EI Escorial-Salamanca 1959; ID., Teología agustiniana de la vida religiosa, El Escorial 1964; J. MoRÁN, El equilibrio, ideal de la vida monástica en San Agustín, Valladolid 1964. En todos ellos hay abundante bibliografía. También y principalmente para lo bibliográfico E. LAMIRANDE, "Un siècle et demi de bibliographie sur l'ecclesiologie de saint Augustin. Essai biblio. graphique": Revue des Etudes Augustiniennes 8 (1962) 1-125.

11 Confess. VII, 18, 24, PL. 32, 745; 19, 25, col. 746; 20, 26 col. 746-747; 21, 27, col. 747-748. 
bro VIII de las Confesiones será el problema de la elección de estado y aquí determinará el abrazar la vida monástica con todas sus consecuencias. Agustín quiere unificarse y deificarse en el ocio santo, en el retiro, cn la contemplación ${ }^{12}$.

Hallada la verdad, Agustín no la conserva para sí solo. La verdad, como los otros valores -la belleza, la virtud, la sabiduría, la justiciaes común a todos, y la primera obligación de cada uno es el tomar conciencia de la propia intimidad y de sus tesoros, de aquellos gérmenes que Dios ha colocado en su imagen. Agustín en el retiro de Casiciaco, ros manifiesta cómo piensa y cómo desenvolverá su actividad, su vida posterior en relación a la comunicación de la verdad. Habla de los amigos, y la razón le pregunta:

R.-Pero dime, ¿por qué estás deseoso de que las personas queridas estén junto a ti?

A.-Porque todos juntos podremos busciar el ser de nuestra alma y del Sumo Dios. De esta manera, aquel que primero consiga llegar a la verdad hará mucho más fácil el trabajo a los otros.

R.- ¿Y si estos tus amigos no quisieran saber nada?

A.-Haría todo lo posible por conseguirlo.

R.-Y ¿si no lo consiguieses, sea porque ya la han alcanzado, o porque juzguen que no podrán encontrarla, o porque verdaderamente tienen otras cosas a qué dedicarse?

A.- Intentaríamos hacer juntos aquello que fuera posible.

R.-iY si su presencia, en vez de ayudarte te impidiese el trabajo, no intentarías huir, dado que no se puede hacer de otra manera?

A.-Ciertamente.

R.-Por consiguiente, no deseas su presencia y su vida por sí, sino en cuanto te pueden ayudar a encontrar la Sabiduría.

A.-Es claro" 13 .

En la comunicación entre amigos la regla era esta: El primero que llegue a la contemplación de la verdad, debe enseñar el camino a los otros.

\section{La ACtitud de Agustín.}

Pero el ecumenismo, la unión, es más una actitud que un principio, ts más una realización concreta de la fidelidad a la verdad y a la caridad

12 Epist. 10, 2, PL. 33, 74; cf. G. Folliet, "Deificari in otio": Revue des Etudes Augustiniennes.

13. Solil. I, 12, 20, PL. 32, 880. 
que un conjunto de principios que se dirigen a los cristianos. $Y$ es precisamente en ésto en lo que ha sido maestro Agustín. Ya desde su conversión comienza a manifestar la fidelidad a la verdad e inicia la comunicación de la misma a sus viejos correligionarios, los maniqueos. Pero antes nos manifiesta cómo ve él la actuación de la Iglesia con todos en un himno o canto a la misma:

"Tú, Iglesia católica, verdadera madre de los cristianos, justamente predicas que Dios, término de nuestra felicidad, sea honrado con perfectísima castidad y pureza...; Tú, con el ejemplo y con la pralabra te dejas ver niña con los niños, fuerte con los jóvenes, tranquila con los ancianos, según lo exija la edad no del cuerpo solamente, sino también del alma.

Por medio de una obediencia casta y fiel sujetas las mujeres a los maridos, no para encenagarse en los placeres sensibles desordenados, sino para formar la familia propagando la prole.

Antepones los maridos a las mujeres, no para rebajar al sexo más débil, sino con los deberes de un amor sincero. Tú haces que los hijos, casi dejándose llevar de una libre elección, se sometan a los padres, y que los padres manden a sus hijos con aquella autoridad que participa de lo sagrado: Unes los hermanos a los hermanos con los nudos de la religión, más íntimamente unidos que aquellos de sangre. Con un recíproco afecto unes los consanguíneos con los que son por afinidad, respetando todo vínculo que, o la naturaleza o bien la voluntad había establecido. A los siervos les mandas que amen a sus amos no tanto por la necesidad de su estado cuanto por el placer de servirles. Tú por obsequio a Dios, supremo Señor de todos, apaciguas los amos en relación a sus siervos, y les dispones más a aconsejar que a castigar. Tú, tanto ciudadanos a ciudadanos, como naciones a naciones y a todos los hombres, no exceptuado alguno, con el recuerdo del origen común, los acercas no sólo para constituir una sociedad, sino diría una misma familia. Enseñas al rey el arte de gobernar a los pueblos, el de estar sujetos al rey, y como maestra incansable vas predicando, a quien honor, honor, a quien afecto, afecto, a quien reverencia, reverencia, a otros el temor, a otros la fortaleza, a otros les amonestas, a éstos la disciplina, a los otros el castigo, a otros el suplicio, haciendo comprender cómo no todo es debido a todos, a todos caridad y a ninguno injusticia" 14 .

Estas palabras suenan como a programa para el futuro obispo todavía laico y poco instruído en las cosas de la religión. Agustín había comprendido desde el principio la función de la Iglesia, y sobre todo está convencido, plenamente convencido, de la verdad de la Iglesia y hace lo posible, usando todos los medios, para hacer partícipes a todos los demás de la verdad, ya que la verdad no es ni tuya ni mía, y no siendo

14 De mor. Eccl, cath. I, 30, 62-63, PL. 32, 1336-1337. 
ni tuya ni mía, será tuya y mía ${ }^{15}$. La verdad será el gran caballo de batalla del Santo, y nos podrá decir que los mártires luchan por la verdad y por ella dan la vida ${ }^{16}$, porque "nada desea el alma tanto como la verdad"17. Mas para hacer a los otros partícipes de la verdad es necesario amarla y comunicarla, y amarla dondequiera se encuentre. Y la verdad se hará común por el amor:

"Amarían de diverso modo la verdad - habla también de los maniqueos_ de los otros, como amo yo sus asertos cuando son verdaderos, no porque sean de ellos, sino porque son verdaderos, y en cuanto son verdaderos ni siquiera son de ellos. Si pues, los aman en cuanto verdaderos, son ya míos y suyos siendo como son bienes comunes de todos aquellos que aman la verdad... Por lo cual, Señor, tus juicios son tremendos: porque tu verdad no pertence ni a mí ni a cualquier otro, sino a todos nosotros, y tú nos llamas públicamente a participarla, con este terrible aviso, de no pretender la posesión privada para no ser privados de ella. Aquel que exige como propio aquello que has puesto a disposición de todos, y pretende retener aquello que pertenece a todos, viene rechazado del patrimonio común hacia lo suyo, es decir, de la verdad a la mentira. En realidad aquel que dice una mentira, lo dice de propia cosecha" 18.

Por eso, antes de nada y para conseguir tal fin es preciso dar muerte a todo aquello que es contrario a la vendad ${ }^{19}, y$ "hacer la verdad en el propio corazón" " ${ }^{20}$. Una vez conseguido esto, nos poidrá dar más tarde la regla áurea: "Todo cristiano bueno y verdadero o auténtico, com. prende que la verdad en cualquier sitio que se descubra, es del Señor" ${ }^{21}$. Estas son las premisas más claras para San Agustín en toda su vida y la fidelidad a la verdad será uno de los principios basilanes en su apostolado.

I. ${ }^{\circ}$ San Agustín y los maniqueos.-Con su experiencia dolorosa en la búsqueda de la veridad puede intentar el acercarse a los otros y asi por ejemplo, en el De utilitate credendi pondrá a disposición de Onorato su experiencia y marcará el camino para la fe tal como él mismo la había

15 En. in ps. 103 s. 2, 11, PL. 1356-1357.

16 En. in ps. 118 s. 20, 8, PL. 37, 1559: (Martyres) vivificati sunt enim ne amando vitam negarent vitam, et negando vitam amitterent vitam ac sic qui pro vita veritatem deserere noluerunt, moriendo pro veritate veritatem viderunt.

17 In Joan. Evang. 26, 5, PL. 35, 1609.

18 Confess. XII, 25, 34, PL. 32, 840.

19; En. in ps. 41, 3, PL. 36, 465 .

20 Confess. X, 1, 1, PL. 32, 779.

21 De doctr. christ. II, 18, 28, PL. 34, 49 。 
vivido, porque dirá que "aquel que cree a los herejes es un hombre que se ilusiona con una cierta imaginación de verdad y de piedad" 22. Agustín piensa en la buena fe de cuantos creen a los herejes y piensa que todos buscan la verdad con la nobleza de espiritu con la que él la ha buscado. En todas sus obras dirigidas a los maniqueos aparece este sentido: los considera siempre como ilusos y engañados por una especie de verdad, como a él le había sucedido. La polémica en ciertos momentos de su carrera se enciende contra los maniqueos, pero cuando esto sucede es porque ha llegado a convercerse de la mala fe y que de hecho no buscan la verdad, sino la comodidad, la cual es muy posible que en la misma doctrina, como doctrina, no se contenga, pero como realidad práctica $s^{\prime 2}{ }^{23}$. Su actitud, bajo este aspecto, necesita una apta distinción: en la doctrina es inflexible, ya que él está convencido de la propia verdad, sin embargo, aprecia las partículas de verdad que encuentra en ellos, sobre todo a través de las diversas interpretaciones del Génesis -De Genesi contra manichiaeos, De Gien. ad litt. imp. lib., De Gen. ad litt., lib. XI-XIII Confessionum-y sabe valorarlas; para las personas todo es simpatía y amor, porque sabe que éste es el camino más fácil de la victoria y de la conversión.

El caso más típico en la controversia maniquea es aquel de Secundino, el cual hacia el 399 escribía a Agustín una carta, en que le invita a volver al rebaño de los maniqueos, alabando su elocuencia, su ansia de verdad y exaltando sus grandes dotes. Las palabras de Secundino tienen un sabor de verdadero proselitismo, convencido de la vendad de su doctrina, haciendo presa en el corazón y en la sensibilidad del Obispo de Hipona :

"Et tamen -ledice- iterum atque iterum supplex deprecor, oro etiam atque etiam obsecro, primum quidem veniam largiri digneris, si quo sermone fuerit tuum titillatum aureum pectus: ardore enim hoc nimio feci, quia nolo te a nostro grege divelli, a quo etiam ego ipse aberrans pene perieram, nisi cito me de iniqua communionis tulissem natura... Nolli te fingere palpare, qui dudum vidisti: noli velle discere, qui potest docere. Dimitte hominum gloriam, si vis Christo placere... Noli ornare mortuos, quia vivorum es ornamentum. Noli comes esse lati itineris, quia Amorrhaeum exspectat: sed ad arctam festina viam, ut consequaris vitam aeternam. Desine, quaeso, utero claudere Christum, ne ipse rursum utero

22 De utilit. cred. 1, 1, PL. 42, 65.

23 Cfr. C. GARcía, Moral maniquea y agustiniana en los escritos antimaniqueos de San Agustín (Tesis de Doctorado, Pont. Acad. Alphonsiana, Inst. Teol. Mor.), Roma 1967, dactil. 
concludaris. Desine duas naturas facere unam; quia appropinquat Domini iudicium. Vae qui accipient, qui quod dulce est, in amaritudinem transferunt" 24 .

Agustín le responde en un libro que es una carta, pero que viene publicado, nos dice él mismo en las Retractaciones II, Io, en forma de libro porque no tiene la dirección. El libro se titula Contra Secundinum manichaeum y según la opinión del Santo es la mejor obra escrita contra los maniqueos. Pero nos interesa su actitud ante este oyente convencido del maniqueísmo. Agustín le da las gracias por su benevolencia hacia él y lo perdona, agradeciendo que lo considere como hombre y le dice:

"Senti de Augustino quidquid libet: sola me in oculis Dei conscientia non accuset" 25 .

No obstante, no le paga en la misma moneda, sino que le da las razones por las cuales ha dejado la secta. No le preocupa su parecer sobre su propia persona, más aún, le permite pensar como quiera: "tantum de ipsa veritate cave quid sentias". La verdad posee una luz bastante diferente de ésta de la fe humana en la conciencia del otro:

"Est enim —prosigue el Santo- quod tecum agi possit: quia non sicut de animo meo nihil amplius possum dicere, nisi ut credas mihi, quod si nolueris, non invenio quid faciam: ita etiam cum de ipsa luce animorum, quam rationales mentes quanto puriores, tanto tranquilius intuentur, falsum aliquid existimas, non tibi potest, si patienter audias, demonstrarique quam sit remotissimum a veritate quod sentis. Sicut enim sensum oculi tui sentire non possum, nec tu mei, sed tantummodo nobis de hac re credere possumus; illam vero speciem utriusque nostrum oculis visibilis subiacet, invicem nobis valemus ostendere: sic de affectionibus animorum nostrorum quas proprias habemus, credamus nobis, si placet; si autem non placet, non credamus: rationem autem veritatis, quae nec mea nec tua est, sed utrique nostrum ad contemplandum proposita, sine pervicaciae caligine, serenatis mentibus pariter attendamus" 26.

La distinción es esencial: La persona de una parte y la verdad de otra. La persona puede sospechar aquello que se quiera, sino se quiere creer a sus razones; pero la verdad es clara y lúcida para todos y se necesita que todos se sometan a la verdad. Agustín no intenta referirse a su

24 Epist. Secundini ad Augustinum 5, PL. 42, 575-576.

25 C. Secund. man. 1, PL. 42, 577-578.

26 Ibid. 2, PL. 42, 578-579. 
persona en concreto, sino que llama a la contemplación de la verdad con ojos serenos y limpios de prejuicios. Todo esto era lo que exigía en sus relaciones con los maniqueos: Los quiere de buena intención, dejar a un lado las desigualdades personales y caminar juntos a la búsqueda de la verdad, para someterse a la misma, ya que su fuerza iluminadora convertirá de esta manera también las conciencias. Cree en la fuerza de la verdad y piensa que la verdad es común a todos e ilumina a todos. Así ha hecho siempre con los maniqueos, después se ha puesto también a esclarecer la doctrina y a exponer la verdad de la auténtica religión refutando de un golpe también el error.

2. San Agustín y los pelagianos.-De la misma manera su actitud general en la controversia pelagiana se ha desarrollado en esta línea. Lleno de benevolencia y comprensión al principio, llega hasta callar el nombre de sus opositores pensando que se darán cuenta de la realidad y no se sentirán heridos, ya que ha usado con ellos de humanidad. Agustín ha hablado antes que en el De peccatorum meritis et remissione et De baptismo parvulorum sobre los pelagianos en discursos y coloquios ${ }^{27}$. Ahora, una vez que se le ofrece la ocasión lo hace en los escritos, pero ha creído conveniente todavía callar los nombres, esperando que sería más fácil la conversión de esta manera ${ }^{28}$. Un poco más adelante ha usado el nombre de Pelagio en alguna parte con alabanza del mismo ${ }^{29}$. En el De natura et gratia confiesa a Timasio y a Santiago ${ }^{30}$ que habiendo leído el libro que le habían enviado, se había alegrado porque veía que su autor se manifestaba católico en la doctrina, pero siguiendo la lectura se llegó a dar cuenta de que dadas las semejanzas que proponía, su pensamiento no era tan recto como dejaba suponer al principio y comenzó su exposición contraponiéndole la doctrina católica ${ }^{31}$.

Agustín no se contentaba con encontrar opositores o contrarios a la doctrina verdadera, como si fuese para él una auténtica complacencia

27 Retract. II, 33, PL. 32, 644.

28 Ibid.

29) Ibid., De gestis Pelag. 22, 46; PL. 44, 346.

30 De nat. et grat. 11, 12 , PL. 44, 252-253; De grat. Christi et de peccat. origin. II, 18,20 , PL. 44,394 ss.

B1 De nat. et grat. 11, 12, PL. 44, 252-253: Fateor Dilectioni vestrae, cum ista legerem laetitia repente perfusus sum, quod Dei gratiam non nëgärềt, per quam solam homo justificari potest. Hoc enim in disputationibus talium detestor et horreo. Sed pergens legere caetera, primo ex datis similitudinibus coepi habere suspectum; cfr. también De gestis Pelag. 23, 47, PL. 44, 347. 
la polémica. No, Agustín no quiere enemigos para poder luchar, quiere que no existan, dado que la Iglesia busca la unidad y la perfección juntamente con el progreso ${ }^{32}$. Esto aparece daramente: Se alegra cuando se encuentra error en aquello que lee; por el contrario, se entristece cuando ve que se presenta la doctrina falsa. En el caso de Pelagio, estamos en el 4I3 ó 4I4 más o menos, escribiendo a Juan de Jerusalén le dice que se sirva de su amistad con Pelagio para atraerlo al buen camino ${ }^{33}$. Agustín ha amado a Pelagio y lo ama todavía, aunque con un sentido diverso: antes lo amaba como a un buen siervo de Dios, ahora lo ama como a un necesitado de corrección. No quería creer a la fama, ya que ésta acostumbra a mentir, pero debe rendirse a la evidencia una vez leídos sus libros ${ }^{34}$.

Lo mismo quiere indicannos en la controversia con Juliano, sobre todo en el Contra Julianum cuando todavía espera en su perspicacia y buen sentido. Por eso dará la regla principal en estos términos, al comienzo del libro VI:

"Responsum est jam libro tuo tertio; respondeatur et quarto: aderit Dominus, ut non solum veritas, sed etiam charitas tibi exhibeatur a nobis. Quae duo quisquis tenuerit, nec fatuus, nea invidus erit. De quibus vittis in principio memorati tui libri multa dixisti. Nam et error veritate, et livor charitate pellendus est" 35 .

Las palabras usadas a veces son fuertes y duras, como fuerte ha de ser a veces la caridad. De esto Agustín está también convencido. Su deseo de convertir a los otros le da opción a usar medios suaves y en ocasiones duros.

$33^{\circ}$ Agustín y otros que opinan en contrario.-La actitud la mantiene en todas sus relaciones, sea con los paganos, sea con los herejes,

32 El P. A. Trapé ha escrito, recogiendo algunos de estos textos con una perspectiva distinta: "Gioia sincera. Il vescovo d'Ippona era un gran polemista, ma non amava la polemica; non amava sopratutto la condanna degli avversari, ma la loro porrezione. E poco si curava delle cose che fossero o ritenesse secondarie, purchè l'essenziale fosse salvo, pumchè su di esso si fosse d'accordo" ("Verso la riabilitazione del pelagianesimo?": Augustinianum 3 (1963) 496-497).

33. Epist. 179, 2, PI. 33, 774.

34 Epist. 186, 1, PL. 33, 816. Tiene palabras de estima para los pelagianos, cfr. Epist. 140, 37, 83, PL. 33, 575 ss.; De peccat. merit. et remiss. II, 16, 25 , PL. 44, 167 ; Epist. 188, 14, PL. 33, 854. Alaba su ingenio y su facundia, cfr. De nat. et grat. 6, 6, PL. 44, 250; C. duas Epist. Pelag. II, 3, 5, PL. 44, 373 ss. $Y$ recuerda de Pelagio su fama de piedad y de santidad, cfr. De peccat. merit et remiss. III, 1,1, PL. 44,185 ss.

35 C. Julian. VI, 1, 1, PL. 44, 821. 
sea también con aquellos cristianos que poseen una opinión diversa de la suya en puntos concretos.

En el De divinatione daemonum nos manifiesta la ocasión del libro, fruto de discusión con algún cristiano que alababa la sabiduría de los paganos en la previsión del futuro. Agustín, primero en diálogo con ellos, y luego en el libro, responde a los paganos por los cristianos, sin citar los nombres de sus' contradictores ${ }^{36}$.

En el 420-42I dirá también a Consentio que no se puede contradecir una doctrina sobre la mentira con otra mentira, sino que es necesario usar de la verdad, y saber que en la Sagrada Escritura los hagiógrafos no mienten ${ }^{37}$. No manifestando el nombre, sino revelando la verdad, ha obrado también en el De bono coniugali, del que sabemos después por Jas Retract, II, 22 (PL. 32, 639) que está escrito contra Joviniano, aunque en el libro no se dé a entender. La verdad prevalece de nuevo y la caridad se coloca a la vista.

Pero una actitud típica la tenemos en los libros De anima et eius origine del año 419-420. Agustín nos cuenta la historia de esta obra en cuatro libros. Un cierto Vicente Víctor ha encontrado en la Mauritania Cesariense en casa de un presbítero español llamado Pedro un opúsculo de Agustín sobre el origen del alma, posiblemente la carta a San Jerónimo sobre el argumento. Vicente escribe dos libros al presbítero Pedro contra aquellas páginas de Agustín, y esta respuesta se la ha enviado a Agustín el monje Renato. Agustín contesta a su vez con cuatro libros: uno al monje Renato, otro a Pedro y otros dos a Vicente Víctor. El mismo nos recuerda en Retrac. II, 56 (PL. 32, 653) que al joven Vicente lo ha tratado con suavidad para instruirlo. Las actitudes de Agustín en este caso son tres, y las tres con los mismos sentimientos. Antes de nada agradece a Renato su gesto y le dice que no tenga nunca miedo de dirigirse a él para alguna cosa cuando piense que escriben contra él, al contrario, le hace saber que le hace mucho bien, ya que puede progresar gracias a la oposición y profundizar más y más en las cuestiones. Solamente tiene un dolor en el alma y es que todavía no lo conoce lo que debía, pues cree que sería una injuria para Agustín hacerle sabedor

36 De divin. daemon. 1, 1, PL. 40, 581: quam recordatum atque completum litteris mandandum putavi, non expressis contradicentum personis, quamvis christiani essent, et magis contradicendo quaerere videretur quis Paganis responderi oporteret.

37 C. mendac. 21, 42, PL. 40, 548. 
de qué piensan los otros acerca de sus opúsculos. Entonces Agustín hace el juicio sobre el joven Vicente, quien sin duda no se ha atrevido a escribir directamente al Santo, primero porque no le conoce y segundo porque él estaba convencido de su parecer y no tenía necesidad de consultar a ningún otro - nec consulendum me putavit, ubi sibi videtur minime dubitandum, sed plane cognitam et certam tenere sententiam-. Si el joven ha escrito en la respuesta algo que ofendiese a Agustín con contumelia, éste cree que lo ha hecho por la necesidad de pensar diversamente, no por el capricho de hacer el mal -non eum conviciantis voluntate crediderim, sed diversa sentientis neccesitate-, porque cuando el interior de otro se desconoce es mejor pensar bien de él, que culparlo de aquello que no se conoce. Quizás lo ha hecho - continúa Agustín- porque me ama, y no quiere que me equivoque en la cuestión que, al menos según él, es clara y verdadera. Por lo cual alaba en él esta grata benevolencia, aunque tenga que reprobar su sentencia ${ }^{38}$. Agustín sabe disculpar el estilo ampuloso y abundante por su joven edad y sabe excusar también los demás vicios y errores producto de la inmadurez, pero lo hace sin inmutarse ${ }^{39}$. Lo ama, y cada vez lo ama más porque ahora quiere mostrarle la verdadera doctrina católica ${ }^{40}$. Para el amigo Renato sólo tiene palabras de alabanza y benevolencia y le manifiesta su espíritu en este libro que le dedica.

Pone en guardia al presbítero Pedro contra los errores de Vicente, pero antes aprecia su humildad, y su laboriosidad en aquellos libros.

"No sé cómo has recibido estos libros; no obstante esto, si es verdad lo que he oído, se dice que cuando te lo han comunicado, tu alegría fue tal que tú, viejo, has besado la cabeza de este joven, y siendo presibitero, la de un laico, dando gracias por haber aprendido lo que ignorabas. En esto no repruebo tu humildad, diré más, alabo el que hayas honrado a tu doctor, y además, no al hombre, sino a la verdad que te ha hablado por medio de él; si puedes demostrar que has recibido la vendad por medio de él. Me gustaría que me enseñases por escrito lo que has aprendido. No pienses que me averguenzo de aprender de un presbítero, si tú no te has avergon-

38 De anim. et ejus orig. I, 1, 1; 2, 2, PL. 44, 475-476: Ubi enim mihi animus erga me hominis ignotus est et incertus, melius arbitror meliora sentire, quam inexplorata culpare. Fortassis amore mei fecit, sciens ad me pervenire posse quod scripsit; dum in eis rebus errare me non vult, in quibus se potius errare non putat. Et ideo debeo etiam ejus habere gratam benevolentiam, cujus me necesse est improbare sententiam...

39 Ibid. I, 3, 3, PL. 44, 476-477.

40 Ibid. I, 20, 35, PL. 44, 494-495. 
zado de aprenderlo de un laico, con una humildad digna de ser predicada e imitada, si has aprendido cosas verdaderas" 41 .

Le ofrece la regla a seguir en el tratar al joven con caridad y con verdad, para no obrar ni contra la una ni contra la otra:

“...absit a manibus atque oculis tuis, id est, assentatio indecens adulantis, et deceptoria lenitudo blandientis. Quod si emendare negligis cum videas emendandum, adversus charitatem facis: si autem tibi emendandus propterea non videtur, quia putas eum recte ista sensisse: adversus veritatem sapis" 42 .

Ni adulación ni una suavidad hipócrita: no se puede herir ni la caridad ni la verdad, es preciso caminar siempre en la vía media, aunque la dificultad se halle en el equilibrio.

Y finalmente hablará al mismo Vicente, recordándole que lo ama, que ama sus talentos, su ardor juvenil, y lo ama no por seguir su parecer, sino para corregirlo, y como espera en su corrección; ésto quiere que sea estimado especialmente en sus libros ${ }^{43}$. Las alabanzas mayores que le hace, después de haber leído sus libros, es que en ellos ha sabido preferir la verdiad a la persona, y una verdad que, aunque no lo sea, él creía que lo era y la prefería a la persona del mismo Agustín. También Vicente había hecho en su obra el panegírico de la elocuencia de Agustín y lo considera como un gran doctor. Agustín ahora le responde que sobre eso de ser peritísimo y doctísimo sabe que no lo es, y sabe además muy bien que en ciertos puntos incluso los indoctos pueden llegar allí donde no pueden llegar los doctores. Por eso alaba el amor a la verdad, y la libertad con que trata a las personas ${ }^{44}$. Agustín se siente un poco padre, se podría decir incluso abuelo y su último consejo al joven es sencillo y sincero:

41 Ibid. II, 1, 1, PL. 44, 495.

42 Ibid. II, 17, 25, PL. 44, 509-510.

43 Ibid. III, 1, 1, PL. 44, 509-510: Non enim sequendum, sed corrigendum te diligo: et quoniam nec corrigi posse despero, nolo mireris me contemnere non posse quem diligo. Si enim te antequam nobis communicares, diligere debui, ut esses catholicus; quanto magis te jam communicantem diligere debeo, ne sis novus haereticus, et ut sis talis catholicus, cui resistere nullus possit haereticus?

44 Ibid. IV , 1, 1, PL. 44, 523-524: Ego autem et me doctissimum et peritissimum nescio, imo vero me non esse certissime scio; et fieri posse non ambigo ut aliquid imperito et indocto cuipiam scire contingat, quod aliquis doctus et peritus ignorat: et in hoc te plane laudo, quod veritatem, etsi non quam percepisti; certe quam putasti, hominem praetulisti; ideo quidem temere, quia existimasti scire quod nescis; sed ideo libere, quia personam non reveritus, elegisti aperire quod sentis. 
"A veces se alaba, se predica y se ama la elocuencia en la esperanza del joven, aunque no posea todavía la madurez y la fe del doctor. Por lo cual con el fin de que comprendas rectamente y pueda no sólo deleitar a los otros sino edificar lo que hablas: conviene que tengas cuidado con tus palabras, huyendo de los aplausos de los otros" 45.

Este mismo clima de caridad y de suavidad se respirará en el $D e$ gestis cum Emerito, contemporáneo del suceso arriba referido o un poco anterior. Agustín endulza su postura, y posiblemente sería preciso ver en él la imagen de la Iglesia que nos había pintado ya en el De mor. Eccl. cath. Parece que Agustín hacia el 420, incluso después, tiene palabras suaves para todos los otros, mientras que las palabras punzantes brotan a veces de su pluma sólo para Pelagio y la tozudez de Julián. En todos los encuentros recordados, sean literarios, sean personales, los principios directivos de Agustín son siempre los mismos y su actitud no cambia, aunque las palabras fuertes suenen aquí y allá.

$44^{\circ} \quad$ Actitud fRente a los donatistas. - Voluntariamente no hemos hablado de los donatistas y de las relaciones de Agustín con ellos, porque queríamos hacer ver que su actitud general se descubre también con los donatistas, y que la cuestión más discutida será preciso enfrentarla, habida cuenta del conjunto de la personalidad y de la obra agustiniana. El problema de la unidad nace en Agustín, como problema eclesial, con el donatismo y sobre todo una vez elevado al sacerdocio. La lucha por la unidad Agustín la defiende en diversos frentes, tanto a través de la predicación y los sermones, como por medio de coloquios y en grandes tratados. En el 393 Agustín asiste al Concilio de Cartago, en el que se ha hablado de entrar más a fondo en la cuestión donatista. Pero ya antes él había querido comunicarse con los donatistas, y había buscado el diálogo. En el 392, siendo todavía presbítero y en ausencia de su obispo, escribe al obispo donatista Maximino, tomando ocasión de la rebautización de un diácono. El tono de Agustín es el acostumbrado en tales ocasiones, como hemos visto. Comienza con estos títulos para el obispo: "Agustín, sacierdote de la Iglesia católica, saluda en el Señor al carísimo $y$ venerable hermano Maximino". Antes de entrar en el argumento,

45 Ibid. IV, 24, 39, PL. 44, 548: Plerumque enim laudatur, praedicatur et amatur eloquium in spe juventutis'; etsi nondum habeat maturitatem fidemque doctoris. Quapropter ut et te recte sapias, et alios non tantummoido delectare possit, verum etiam aedificare quod loqueris; curam te oportet gerere de sermonibus tuis, remotis plausibus alienis. 
expone la razón o las razones de estos títulos, y escribe: "Te he llamado señor, porque está escrito: "vosotros, oh hermanos, habéis sido llamados a la libertad; sólo que esta libertad no sea un pretexto para la carne, sino que por medio de la caridad haceos servidores los unos de los otros" (Gal 5, I3).

"Por consiguiente, ya que con escribirte te hago un servicio, bien puedo llamarte señor mío, para obedecer al único y verdadero Señor nuestro que nos ha mandado obrar así. En cuanto al títuilo de carísimo, Dios bien sabe que no sólo te amo, sino que te amo como a mí mismo, desde el momento que tengo la conciencia de querer para ti todo el bien que quiero para mí. Sin embargo, he añadido el título de venerable, no por rendir honores a tu episcopado, ya que tú para mí no eres obispo; no te ofendas por esto, sino consérvialo como dicho por mí por la sinceridad que debe existir en nuestros labios: Sí, sí; no, no (Mt 5, 37). De hecho no es un secreto para ti, ni para ningún otro que nos conozca, que tú no eres mi obispo, y que yo no soy sacerdote tuyo; ahora bien, yo te he llamado voluntariamente venerable, es decir, digno de honor, porque tú eres un hombre, hecho a imagen y semejanza de Dios, puesto en honor por el mismo orden y derecho natural, a fin de que este honor se halle comprendido dentro de su dignidad... Finalmente, tú sabes por qué te he llamado hermano: por el mandamiento que nos ha dado Dios de tratar como a nuestros hermanos incluso aquellos que no quieren ser nuestros hermanos; y esto viene muy bien con el argumento que quiero tratar" 46 .

Agustín cree en la buena fe de Maximino y espera en su conversión ${ }^{47}$, mas llora el escándalo de la división, la división del único Cristo no sólo en la plaza, sino también en la familia:

" ¿No lloramos que el marido o la mujer laceren el cuerpo del mismo Cristo, con dos comuniones diferentes; ellos, que han llamado a Cristo como testimonio de la fidelidad? Si por la moderación, prudencia y caridad que debemos sentir hacia Aquél que ha derramado su sangre por nosotros, en los referidos lugares desapareciera este grave escándalo, este gran triunfo del demonio, este grave daño de las almas, ¿quién podrá expresar con palabras qué palma te preparará el Señor siempre que de ti viniese un ejemplo, digno de imitación y capaz de llevar la salvación a todos los otros cristianos, que por toda el Africa yacen miserablemente en el error? Temo grandemente que, no viendo mi corazón, tú puedas pensar que te hable, no con una caridad sincera, sino con ficción. $Y$ sin embargo no puedo hacer nada mejor que manifestarte a ti mis palabras y a Dios la intención" 48.

46 Epist. 23, 1, PL. 33, 94-95.

47 Ibid. 2.

48 Ibid. 5, PL. 33, 97. 
Su deseo es poder dialogar, tener el coloquio en privado y sin ruido con él ${ }^{49}$, pero se necesita olvidar la historia, olvidar el pasado, perdonarse mutuamente y caminar a la búsqueda de la verdad sin prejuicios. Agustín espera respuesta y cuando la haya recibido leerá ambas cartas a los fieles. Esto lo hará en ausencia de los soldados, ya que no quiere imponer la verdad con el miedo a la fuerza civil:

"Ut omnes qui nos audiunt intelligant non hoc esse propositi mei ut inviti homines ad cuiusquam communionem cogantur, sed ut quietissime quaerentibus veritas innotescat" 50 .

La actividad de Agustín en favor de la unidad ha sido inmensa. El ha querido decididamente los encuentros personales, aunque haya tenido bien pocos, debido a motivos extraños a sus intenciones, ordinariamente porque no osaban medirse con él ni medir una verdad que de por sí no regía. El éxito más espléndido para Agustín fue la preparación de la grande conferencia interconfesional, podemos decir, de Cartago del 4II, de la que incluso él fue el campeón, tanto en la preparación, como en el desarrollo de la misma y en la propaganda posterior.

"Agustín, al parecer, frecuentó asiduamente las asambleas conciliares de esta época. Lo vemos tomar parte cada día más importante en la orientación de la lucha por la unidad. Sin título alguno que hiciera pesar su autoridad, sin manifestar ninguna demora en el someterse a las decisiones tomadas, su influjo aparecía capital, sobre todo cuando se trató de preparar la gran Conferencia del 411 , de hacer triunfar la verdad y de prolongar su éxito" 51.

Pero cuando Agustín ha visto más de cerca el cisma, ha sido al ser elegido obispo de Hipona. Desde ahora su acción contra los donatistas, o mejor, en pro de la unidad de los donatistas con los católicos, se multiplicó, es, casi diría, incomprensible.

"Predica la unidad en Hipona, pero también en Cartago, en HippoDiarrhytos, en Constancia, y también en Cesárea, a 800 kilómetros de Hipona, por los caminos de la época. Viaja con el fin de documentarse acerca del cisma a Musti, a Membresa, Abitinia y Assuras. Escribe a muchos obispos, a a laicos influyentes de la secta.

Ibid. 6, PL. 33, 97-98.

Ibid. 7, PL. 33, 98.

51 R. CREspín, Ministère et Sainteté. Pastorale du clergé et solution de la crise donatiste dans la vie la doctrine de saint Augustin, Paris 1965, 133. 
Si a todo esto se añade la redacción de los grandes tratados antidonatistas, la acción de Agustín cabe sus propios compañeros y cabe los magistrados, sus intervenciones en los concilios, la preparación de la gran Conferencia con los cismáticos y la explotación de este suceso, quedamos estupefactos ante la enorme actividad desarrollada por el obispo de Hipona al servicio de la unidad" 52 .

Los encuentros personales de Agustín han sido escasos: Un primer coloquio tenido en Thubursicu con Fortunio en el que se ha hablado de los puntos más relevantes que dividían los espíritus. Agustín quedó satisfecho de esta entrevista, aunque le disgustó la agitación de la muchedumbre, porque en Fortunio ha encontrado una buena voluntad y una mente abierta ${ }^{53}$. Otro encuentro no tan feliz lo ha entretenido con Crispín de Calama, el cual más por mala voluntad quizás, que por falta de memoria no se recordaba, o hacía que no se recordaba. Esto le sentó mal a Agustín ${ }^{54}$.

Las relaciones epistolares son más abundantes, y ordinariamente se preferían éstas porque podían conservarse y leerse ante los fieles ${ }^{55}$. Mas para este cambio de impresiones y para el diálogo las condiciones exigidas por Agustín eran claras. No quería improvisarse dialogantes o destinatarios. Justo es decir que a veces la correspondencia era ocasional, es decir, aprovecha como base un suceso y lo eleva al momento a categoría ${ }^{56}$. Las condiciones para Agustín son la buena disposición de espiritu o al menos un espiritu abierto al diálogo y a la verdad; quiere después obispos cuya personalidad y comportamiento precedente, deje esperar buena acogida, y lo hace siempre con cortesía y prudencia, tratando de demostrar la verdad a los lectores, no de atacar a las personas. Agustín ha trabajado muchísimo por la unidad, pero el balance final sería casi negativo, aunque el silencio se ha impuesto, y este silencio podría significar la medida de su éxito.

Brilla otro aspecto en la polémica, aspecto que a decir de Monceaux, constituye la originalidad del obispo de Hipona. Ha hecho intervenir e interesar a los laicos en el problema de la unidad, bien leyendo lo que él hablaba, o escuchando sus sermones, o también desde el principio con la

\footnotetext{
52 ID., o. c. 143.

53 Epist. 44, 5, 12, PL. 33, 179.

54 Epist. 51, 1, PL. 33, 191.

55 R. Crespín, o. c. 150-151.

56 Así tenemos el caso de Maximino, del que hemos hablado ya, el caso de Crispín de Calama que impone el bautismo a sus colonos, o el caso de Fortunio, ocasión de su viaje.
} 
composición de su Psalmus contra partem Donati con aquel estribillo, Omnes qui gaudetis de pace, modio verum iudicate. Más que los sermones, que son muchos, acerca de la doctrina donatista, sirven a la causa de la unidad las cartas de Agustín, en las que aparece el deseo de hacer intervenir, tanto a los laicos católicos como a los donatistas, en lo tocante a la verdad de la historia y de la doctrina. Una parte muy positiva en su controversia se contiene en el progreso del conocimiento de Agustín en torno a la historia del cisma, de sus orígenes y del desarrollo del mismo. Apelaba no sólo a la Escritura, sino también a la historia: verdad histórica y fidelidad, caridad y amor.

No hay necesidad de recorrer paso a paso los diversos momentos de esta emocionante lucha por la unidad. Cuentan los hechos, cuentan a su vez las obras escritas, cuentan las cartas y los sermones ${ }^{57}$. Sólo queda la intervención de la autoridad civil en la cuestión donatista y la actitud de Agustín. Antes de poder emitir un juicio sobre el suceso y sobre su opinión positiva acerca de la intervención de la autoridad civil, es necesario recordar cómo se comportó con los otros y cuáles eran los principios que lo guiaban. Haremos una breve alusión a ello.

\section{San Agustín y la aUtoridad CIVIL en materia Religiosa.}

En cuanto a la intervención civil, en San Agustín existe una evolución, quizá con la posibilidad de ser vista en cinco estadios sucesivos diversos:

"El primero ocupa los casi diez primeros años de su ministerio pastoral en Hipona, al principio como simple sacerdote y después como obispo, es decir, del 391 al 400. Un segundo se extiende escasamente a través de cinco años, o sea, del 400 al 405 . El tercero comprende los años 405, 407408; el cuarto otros tres, del 408 al 411, y el quinto ya iniciado en el 408409, del 411 en adelante" 58 .

En la controversia donatista $\rightarrow \mathrm{y}$ a esta se refiere la actitud tomada ante la autoridad civil- aparecen estas etapas: él mismo nos ha confiado

57 Cfr. R. CRspín, o. c.; J. Vodopivec, l. c.; A. Turrado, l. c. y algunos articulitos de Ch. BOYER en Unitas.

58 V. Monachino, "El pensamiento de San Agustín sobre el empleo de la fuerza política al servicio de la religión": Contribución Española a una misionología agustiniana, Burgos $-955,89$. 
en más de un lugar cuál era su pensamiento inicial. Escribiendo a Vicente, el rogatista, le decía en el 405 :

"Mi opinión era, al comienzo, que ninguno debía ser conducido a la fuerza hacia la unidad de Cristo, sino más bien se debía trabajar con la palabra, combatir con la discusión, vencer con la razón, para no convertir en católicos fingidos aquellos que conocemos como herejes declarados" 59.

La misma opinión manifestaba en la obra ahora perdida Contra partem Donati, del 397, como nos recuerda en Retrac II, $5^{60}$.

Después de años de trabajo por la paz y la unidad, Agustín se da cuenta de que la Iglesia gana poco frente a los donatistas, y comienza, se diría, a dudar de la fuerza de la verdad y de la potencia de la persuasión. En su interior otra convicción se abre camino:

"La intervención del estado se requiere para crear un clima de libertad y un ambiente de paz en el que sea posible hacer la propaganda de la verdad católica, en el que se conceda a cada uno seguir la religión que quiera y a los donatistas también la conversión, sin temer las represalias por parte de los circunceliones" 61.

Así comienza a expresarse en la Epist. 5i a Crispín de Calama, y poco después en la epístola contra Parmeniano o Contra Epistolam Parmeniani, para reafirmarla y profundizarla en Contra litteras Petiliani y en la Epistola contra Donatistas. Aquí se dan también razones teológicas: la fe sigue libre, como libre debe ser también la elección del bien, ya que ninguno puede ser bueno, si no quiere. Pero la represión no obliga a hacer el bien, sino que confina el mal en el claustro de la propia conciencia ${ }^{62}$

En el 405 el Emperador igualaba a los donatistas con los herejes para todos los efectos legales, decretando la supresión de la Iglesia cismática y la obligación a los disidentes de volver a la unidad bajo pena de graves sanciones. La Iglesia, dirá Agustín, ha pedido esta ley, no para perseguir a los donatistas, sino para defenderse a sí misma. Y la misma consideración viene manifestada y expuesta ampliamente en

59) Epist. 93, 5, PL. 33, 329.

60 Esto mismo prueba la actividad unionística de San Agustín, que hemos tratado de desvelar brevemente aquí. En torno a estos principios generales pueden engranarse multitud de textos agustinianos, en especial de las obras antidonatistas y de las cartas y que están ya en canteda.

61 V. Monachino, art. cit., p. 96.

62 C. litt. Petil. II, 83, 184, PL. 43, 315. 
Contra Cresconium. Si es verdad que los argumentos a los cuales recurre aquí vienen a decirnos nuevamente que el estado debe defenderse, pensando un poco en la religión como organismo del Estado, es también cierto que Agustín no defiende todavía ni admite la conversión oficial, es decir, por la fuerza. De hecho él no ha querido la aplicación integral de las nuevas leyes. La aplica, pero con caridad, humanidad y suavidad.

Poco después, entre el 407 y el 408, Agustín se deja ilusionar por los resultados de la aplicación de estas leyes, recibiendo él mismo confesiones en las que se le decía que daban gracias a Dios porque, mediante aquellas leyes, habían encontrado el buen camino y vivían como buenos cristianos ${ }^{63}$.

En este tiempo profundiza en el concepto de libertad y llega a una "libertad de perdición", tras el edicto de tolerancia del 4Io, trabajando incansablemente por la celebración de un Concilio para pedir al Emperador la abrogación de aquel edicto ${ }^{64}$. Y aunque por una parte se halla trabajando en lo civil, por la otra continúa la preparación de la gran Conferencia de Cartago entre los partidos contendientes, conferencia tenida en el año 4 II.

Llegados a este punto, no sabemos cómo ni por qué Agustín elabora su doctrina sobre la "coercitio", o sobre el "compelle intrare". Del 4I I en adelante se pone de relieve este pensamiento agustiniano. Ya había dicho algo semejante en Contra Cresconium III, 5r, 56 (PL. 43, 527) y en la Epist. 93 a Vicente, el rogatista, pero ahora aparece en su concepción más neta en la Epist. 185 al' Conde Bonifacio. Los reyes - dirá él一 tienen el derecho y el deber de procurar la unidad de la Iglesia y la represión de la herejía, y la Iglesia puede llamarlos legítimamente en su ayuda. Pero la razón, para Agustín, no radica en la autoridad misma, sino en la autoridad del cristianismo. Siendo ahora cristianos los emperadores tienen el deber, por el hecho de ser cristianos, de extender la verdad y de custodiar la unidad, y esto, sobre todo, contra las insidias $y$ las represalias de los circunceliones y de los donatistas en general. Es verdad - dirá el Santo en esta Carta- que será mejor método dirigirse a Dios por amor, pero si no se quiere por ese medio, al menos deben acercarse por el temor. Muchos, en efecto, necesitan del temor para evitar el mal, y evitando así el mal, amarán el bien. La Iglesia no

63 Cfr. Epist. 93, 1, 1, PL. 33, 321; Epist. 185, 3, 13, PL. 33, 798.

64 C. Crescon. I, 24, 27, PL. 43, 722. 
ha hecho otra cosa que poner en práctica el precepto del Evangelio, en la parábola del Señor sobre el banquete nupcial:

"El mismo Señor nuestro invita a los convidados a su cena, y después los obliga. Los siervos le responden: "Señor, se ha hecho todo aquello que has mandado, pero todavía hay mucho puesto libre". Y el Señor les dice: "Salid por las calles y a cuantos encontréis, obligadles a entrar, cogite intrare". En los primeros completó la obediencia invitándoles con suavidad, mientras que a los segundos obligados, los obligó a obedecer...".

Después explica aquel cogite intrare diciendo:

"Aquellos que se encuentran en la calle y en las aldeas, es decir, en la herejía y en el cisma, son obligados a entrar por el poder que la Iglesia ha recibido en tiempo oportuno, por don de Dios, por medio de la religión y de la fe de los reyes. Por consiguiente, no deben enfadarse o quejarse los donatistas porque son obligados, sino lo que deben hacer es mirar a qué son obligados. El banquete del Señor es la unidad del Cuerpo de Cristo, no sólo en el sacramento del altar, sino en la vínculo de la paz" 65.

En el libro Contra Gaudentium I, 25, 28 (PL. 43, 722-723) vuelve sobre la misma parábola y hace la misma exposición. La Iglesia persigue y persigue para convertir, pero su persecución difiere de la persecución que hacen los otros: Ella, contrariamente a lo que hacen los impíos, persigue por amor, para alejar del error, para destruir en sus enemigos la vanidad y el orgullo, para hacerles partícipes del beneficio de la verdad, para librarles de la muerte y de la perdición, para asegurarles la salvación eterna ${ }^{66}$.

Las razones que han obligado a Agustín a definir esta doctrina nos han sido ofrecidas por él mismo, sobre todo en las Retract. II, 5, hablando del opúsculo Contra partem Donati, donde, después de haber indicado cuál era su opinión cuando lo escribe -en el 397-, añade: "Entonces no me gustaba verdaderamente, porque no había experimentado todavía, o el mal que podía o se atrevía a hacer su impunidad, o cuánto podría contribuir a mejorar la diligencia de la disciplina". Las dos razones principales eran estas: $\mathrm{El}$ mal, las represalias, las emboscadas de los turbulentos circunceliones, y el bien que se podía esperar de la fuerza, bien que experimentó después del 407-408.

$¿$ ¿Ha cambiado esto la actitud fundamental de Agustín, hecha de

65 Epist. 185, 6, 24, PL. 33, 804.

66 Ibid. 2, 11, PL. 33, 797. 
suavidad, de caridad y de benevolencia? ¿Qué piensan los autores de esta teoría de Agustín? Para hacernos un juicio sobre ella podemos decir ahora cómo la juzgan los demás:

"Es una teoría creada con motivo del donatismo. A los ojos de Agustín el donatismo poseía un carácter propio, que lo distinguía de las otras herejías. De hecho, nunca ha pensado en reclamar la aplicación de la fuerza contra los otros herejes y aún menos contra lọ paganos, los maniqueos o los judíos" 67 .

Y se citan en nota las siguientes palabras de Monceaux ${ }^{68}$ :

"A ses yeux, le cas du Donatisme n'etait pas celui des herésies proprement dites; c'était affaire de police, plus que de religion".

El P. Congar habla así del tema:

"Nosotros no vemos casi otra cosa que las condiciones de la libertad de conciencia personal: Agustín veía sobre todo el derecho de la justicia y de la verdad, condicionando ésta completamente a aquélla. Hemos sido arrastrados a asemejar tal uso de la fuerza a aquel otro uso de la fuerza sin importarnos cuál es. Para Agustín su uso (en el sentido fuerte del usus agustiniano) en provecho de la verdad, es decir, de la justicia, era, no sólo moralmente, sino también ontológicamente o axiológicamente diferente de su uso en provecho de la mentira, del desorden y de la injusticia, porque realizaba el ser verdadero de las cosas, conforme al pensamiento de Dios" 69 .

H. Janes ha estudiado el lado teórico y el práctico de ésta teoría, afirmando en la teoría un Agustín defensor de la intervención del Estado y un fundamento que surge en la Escritura, y llegando en la práctica a decirnos, en la conclusión de sus artículos:

"Aparece finalmente, que en la práctica, San Agustín ha conservado simpre una preferencia por la paciencia y la difícil persuasión, como lo atestigua entre otras cosas su postura hacia Emeritus en el 418. Creemos poder afirmar que, según él, la caridad ha precedido siempre o prevalecido sobre la autoridad y que el recurrir a ésta no estaba justificado sino porque estabia al servicio de la caridad. Creemos también poder afirmar que en un clima de paz y de respeto mutuo de las personas y de sus bienes,

$67^{\circ}$ V. Monachino, a. c. 99.

68 P. MoncEaux, Histoire de l'Afrique chrétienne VII, 229.

69. Y. M. J. CoNGAR, Introduction. Traités anti-donatistes, I (Oeuvres de saint Augustin 28), Desclée de Brouwer 1963, 25. 
el obispo de Hipona no habría renunciado a su preferencia por la libertad de conciencia, cuyos méritos había expuesto hasta el presente" 70 .

Ultimamente Crespín, después de un estudio cuidado sobre los textos de San Agustín, y también de los autores que tratan el argumento, concluye:

"Cuando el obispo de Hipona se declara ganado a los métodos de represión y de constricción, no es necesario entender que las medidas administrativas tomadas contra el cisma pueden, en su pensamiento, suprimir y sustituir el paciente esfuerzo de persuasión" 71 .

\section{Y finalmente :}

"Las violencias de los donatistas han obligado a Agustín a aceptar la protección de las leyes, que le permitían el proseguir en condiciones menos peligrosas su campaña de predicación y discusión. Si él ha defendido las medidas de represión, que no había solicitado, es, sobre todo, porque no podía dar razón a las críticas de los donatistas y condenar la iniciativa imperial. Así quizá no quèría desolidarizarse con el episcopado católico, favorable, en su conjunto, a esta política de firmeza" 72 .

Agustín quiere mantener la unidad religiosa, mientras que el imperio sin duda busca la unidad política. Agustín no podía estar dispuesto al juego, pero ha debido pagar tributo a la incertidumbre, y quizá también a la malicia de los hombres.

"La voluntad tan frecuentemente manifestada de dialogar y de convencer - termina Crespín en el 1965- nos parece la más característica del pensamiento profundo de Agustín" 73 .

El hecho está ahí: San Agustín ha llegado a su teoría de la coercitio o del cogite intrare después de una larga lucha por la unidad y sobre todo, se necesita tener en cuenta esto, después de la Conferencia del 4II. Pero no estaría fuera de lugar recordar que también el problema de la gracia iniciaba su curso, y que en ciertos aspectos la teoría se

70 H. JANS, "De praktijk van de geloofswang volgens Augustinus correspondentie": Bidragen 22 (1962) 247-263, con resumen en francés, p. 263-265, del que copiamos p. 264-265. Y el artículo precedente llevaba por título "De vedantwoording van geloofswang tegenover ketters vodgens Augustinus correspondentie": Bijdragen 22 (1961) 133-159.

71 R. CRESPÍN, o. c. 169.

72 ID., o. c. 170.

73 ID., o. c. 175. 
resiente de su opinión sobre la dependencia absoluta de Dios, sobre sus derechos, pero sobre todo sobre aquello que es más importante, sobre la libertad que permanece incluso después de la corrección por la fuerza, como aludía en el Contra Gaudentium: Dios hace que aquellos que no querían, ahora quieran.

Contrasta con la teoría del Cogite intrare el sermón sobre los pelagianos, en el que se encuentra toda la práctica de Agustín, y es más o menos del mismo tiempo en que madura la teoría. En aquél Sermón 294, 20 (PL. 38, I348) dice: "Si lo podemos, trataremos de obtener de nuestros hermanos, que, a pesar de todo, no nos llamen heréticos; cuando nosotros, quizá si quisiéramos, podríamos llamar heréticos a aquellos que discuten sobre ciertas cosas: y sin embargo no lo hacemos. La madre bondadosa los soporte misericordiosamente, que tienen necesidad de ser sanados, los guíe, que tienen necesidad de ser instruídos, a fin de que no tenga que llorarlos muertos. Van demasiado lejos, verdaderamente demasiado, apenas se puede soportar; soportarlo todavía es señal de gran paciencia. Pero no abusen de la paciencia de la Iglesia; corríjanse, es su bien. Usamos el tono de exhortación como conviene a amigos; no litigamos como si fuésemos entre enemigos.

"Hablan mal de nosotros, lo soportamos; pero no hablen mal de la regla, no hablen mal de la verdad, no contradigan a la santa Iglesia que cada día se fatiga por la remisión del pecado original en loṣ niños. Se trata de algo bien fundado. Quien yerra discutiendo de otras cuestiones todavía no diligentemente esclarecidas, todavía no determinadas plenamente por ila autoridad de la Iglesia, es digno de ser soportado: en semejantes cuestiones se debe soportar el error; pero no se debe avanzar tanto que se descentre el fundamento mismo de la Iglesia. Esto no va bien; quizás nuestra paciencia todavía no es digna de blasfemia; no obstante debemos temer el poder llegar a ser culpables de negligencia. Queridísimos hermanos, basta. Comportaos con ellos, quienes de entre vosotros los conocen, comportaos con ellos con amistad, con fraternidad, con dulzura, con amor, con dolor. La piedad ponga en obra todo aquello que tiene en su poder, porque, después, la impiedad no podrá, no deberá ser amada" 74.

No obstante hay que reconocer que la teoría ha quedado como simple teoría, y que solamente se aplica teóricamente a los donatistas, no a los otros herejes. Así en línea teórica, éste sería su pensamiento a partir

74 La cronología del Sermón no es clara. Trapè habla del año 412 , en cambio A. Kumzelmann, "Die Chronologie der Sermones des hl. Augustinus": Miscelianea Agostiniana II, 468, piensa, siguiendo a Migne, que se trataría de un sermón predicado el 27 de junio del 413. 
del 4I2, aunque sean pocos los pasos en los que trata el argumento ${ }^{75}$ En línea práctica, Agustín sigue su actitud, ya conocida, continúa la búsqueda del diálogo y de los coloquios, usa todos los medios a fin de que las decisiones imperiales no se pongan en práctica 0 , si alguna se debe poner, se haga con dulzura y suavidad. Pero tanto con los donatistas como con los pelagianos su actitud es la verdad y la caridad. Así nos podemos referir al caso de Emérito. Agustín una vez llegado a Cesárea y sabiendo que se encuentra aquí va a su encuentro y lo halla en la plaza, caminando juntos a la Iglesia. Agustín ha hablado bastante sobre la paż, la caridad y la unidad. Sucedía esto en el $4 \mathrm{r} 8$, y en el De gestis cum Emerito ha expresado la marcha de este encuentro, llevado a čabo con caridad y afabilidad. En línea práctica Agustín no ha aplicado aquella que se ha dado por llamar con el nombre de su teoría, del "compelle intrare".

\section{COŃCLUSIONES Y PRINCIPIOS.}

A lo largo de esta exposición hemos topado con los principios fundamentales directivos de la conducta del Santo, pero que venían regidos por una ideología decidida y convencida:

r. ${ }^{\circ}$ Agustín conoce y comprende cuánto cuesta el llegar a la verdad y esto le ha dado una experiencia, trágica a veces, que quiere poner como ejemplo a los otros, v. gr.: en De utilitate credendi.

2. Por eso ante todo defiende una fidelidad máxima a la verdad y cree que la verdad está en la Iglesia católica, y por consiguiente lucha por la verdad, sufre por la verdad, dice la verdad, porque siente la obligación íntima, profunda de la verdad que llama dentro. Esta fidelidad a la verdad le impone muchísimos sacrificios.

$3^{\circ}$ - Hallada la verdad, siente la obligación apostólica y pastoral de comúnicarla a los demás y piensa que no daría su servicio y su contribución a la Iglesia, si no se diese todo él a la expansión de la verdad. Toda su lucha por la unidad, que es lucha por el triunfo de la verdad, reviste un sentido verdaderamente apostólico y pastoral, y quiere llegar a la conversión, a la verdadera fe de aquel que yerra y no cree. Quiere

75 Cfr. Epist. 93, 5, PL. 33, 323; Epist. 173, 10, PL. 33, 757; Epist. 185 , 24, PI. 33, 803-804; C. Gaudent. I, 25, 28, PL. 43, 7225; Serm. 112, 8, PL. 38, 647-648. 
convertir, quiere hacer volver al buen camino, y esta actitud nace de una fe profunda y segura, y de una obligación que ha contraído por amor a Cristo.

4. Pero la verdad, creadora de unidad, la comunica una persona y la comunica a una persona, y de ahí que su segundo principio sea el respeto a la persona del otro, basado en la verdad y en la fraternidad humana y cristiana. $Y$ amando puede hacer aquello que quiere y decir aquello que desea. Esta caridad puede ser dura a veces - al igual que un padre hace con su hijito-y puede, por consiguiente, prohibir hacer el mal incluso por medio del poder civil, por la fuerza, ya que la caridad mira al bien superior y éste es lo que desea para los otros. Así podrá decir con un principio de oro "que ninguno puede ser verdaderamente amigo del hombre, si no lo fuese antes de la misma verdad" "76. Por este mismo hecho no se oponía a la libertad ni de la persona humana, ni de las buenas obras, ni del acto de fe, porque la mente no desea más que la verdad ${ }^{77}$.

$5^{\circ} \quad$ Otro hecho, a través de toda su vida, ha sido la claridad en la exposición de la doctrina católica, sin adulación de los otros, e investigando las fuentes y los puntos de contacto entre los contendientes. Los casos más típicos los tenemos en sus tres grandes polémicas: contra los maniqueos, contra los donatistas, y contra los pelagianos. Y aún más esta claridad y esta sinceridad la ha demostrado en el hacer partícipes incluso a los fieles laicos del problema de la unidad, de los errores, de la doctrina verdadera, llegando sobre todo a una depuración, hoy diríamos a una reforma o renovación de ciertas formas de vida en las costumbres y maneras cristianas, y dando las reglas para no agravar demasiado la religión con preceptos duros o mejor, dice él, con presunciones humanas ${ }^{78}$.

6. Quizás el resumen más claro de su actitud en el problema de la unidad por medio de la caridad en defensa de la verdad lo tenemos en el modo cómo nos había descrito la Iglesia ya al principio, acomodándose en la caridad a las diferentes necesidades: "Enseñas a los reyes el arte de gobernar los pueblos y a los pueblos el de estar sujetos a los reyes, y como maestra incansable vas predicando a unos el honor, a otros el

\footnotetext{
76 Epist. 155, 1, 1, PL. 33, 667.

77 In Joan. Evang. tr. 26, 5, PL. 35.

78 Epist. 55, 19, 35, PL. 33, 221. Citado por el mismo Santo Tomás en I-II, q. 107 , a. 4 c.
} 
afecto, a unos la reverencia, a otros el temor, a unos la fortaleza, a otros la admonición, a unos la disciplina, a otros el castigo, a unos el suplicio, haciendo ver cómo sea debido no todo a todos, a todos la caridad y a ninguno la injusticia" ${ }^{79}$. Y así aun después de su cogite intrare, podía decir en el 418 :

"Por ésto sudamos, por ésto trabajamos, por ésto peligramos de continuo entre sus armas y las cruentas furias de los Circunceliones, y toleramos con cierta paciencia dada por Dios a los que aún restan, mientras el árbol busca el ramo, mientras el rebaño busca la oveja perdida del redil de Cristo. Si estamos dotados de entrañas pastorales, debemos aventurarnos por cercados y espinos. Con los miembros lacerados busquemos la oveja y llevémosla de nuevo con alegría al Pastor y príncipe de todos" 80.

J. Morán, O. S. A.

79 De mor. Eccl. cath. I, 30, 63, PL. 32, 1336-1337.

80 De gestis cum Emerito 12, PL. 43, 706. 